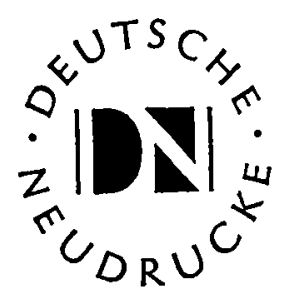




\section{Deutsche Neudrucke}

herausgegeben von Karl Stackmann Mittelalter, Erich Trunz Barock, Paul Böckmann und Friedrich Sengle s8. Fabrbundert, Arthur Henkel Goetbexeit, Walter Killy s9. Fabrbundert

\section{REIHE: BAROCK}

Herausgegeben von Erich Trunz

3

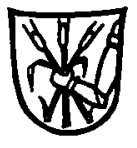

Max Niemeyer Verlag Tübingen 1975 


\title{
Martin Opitz
}

\author{
Weltliche Poemata \\ I 644 \\ Zweiter Teil \\ Mit einem Anhang: \\ Florilegium variorum epigrammatum
}

\author{
Unter Mitwirkung von \\ Irmgard Böttcher und Marian Szyrocki \\ herausgegeben von Erich Trunz
}

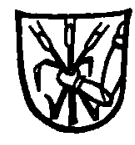

Max Niemeyer Verlag Tübingen 1975 
Die Deutschen Neudrucke werden in Zusammenarbeit mit der Germanistischen Kommission

der Deutschen Forschungsgemeinschaft herausgegeben

Für die freundliche Überlassung des Originaldrucks

danken wir der Staats- und Universitätsbibliothek Hamburg

(C) Max Niemeyer Verlag Tübingen 1975

Printed in Germany

Reprografischer Druck : Fotokop GmbH Darmstadt

Satz und Druck des Nachworts: Eugen Göbel Tübingen

Einband: Heinr. Koch Tübingen 